\title{
LA CASA DESIMAGINADA: EXTRACTIVISMO Y LOS FANTASMAS DEL CAPITALISMO GLOBAL EN GEOLOGÍA DE UN PLANETA DESIERTO DE PATRICIO JARA
}

\author{
UNIMAGINED HOME: EXTRACTIVISM AND THE GHOSTS OF GLOBAL \\ CAPITALISM IN PATRICIO JARA'S GEOLOGY OF A DESERT PLANET
}

\author{
Francesco Di Bernardo \\ Falcultad de Filosofía y Letras, Benemérita Universidad Autónoma de Puebla \\ México \\ francesco.dibernardo@outlook.com
}

\begin{abstract}
Resumen: El presente artículo propone una lectura de la novela Geología de un planeta desierto (2013) del escritor chileno Patricio Jara, enmarcando la discusión en el contexto del análisis de las características de la "literatura de los hijos" en Chile. El artículo discute la crítica del modelo neoliberal y extractivista propuesto en la novela utilizando el concepto de "comunidad desimaginada" teorizado por Rob Nixon. Asimismo, el presente trabajo interpreta los aspectos espectrales de la novela como una metáfora para llevar a cabo una crítica de los mecanismos ocultos del capitalismo global.
\end{abstract}

Palabras clave: Jara. Literatura chilena contemporánea. Literatura de los hijos. Realismo. Irrealidad.

\begin{abstract}
The present article proposes a reading of Patricio Jara's novel Geology of a Desert Planet (2013), framing the discussion in the context of the analysis of the feature of the literatura de los hijos generation in Chile. Deploying Rob Nixon's theory of the "unimagined communities", the article discusses the critique of the neoliberal and extractivist model proposed in the novel. Similarly, the present work reads the spectral aspects of the novel as a metaphor employed to provide a critique of the hidden mechanisms of global capitalism.
\end{abstract}

Keywords: Jara. Contemporary Chilean Literature. Literature of the children. Realism. Irreality.

Recibido: 04/06/20. Aceptado: 14/06/21. 
E lescritor y periodista chileno Patricio Jara (Antofagasta 1974) es autor de novelas que exploran las regiones del norte de Chile. Antofagasta, la ciudad natal del escritor, es protagonista de algunas de sus novelas previas tales como El sangrador (2002) que narra la historia del primer dentista del área del norte de Chile, y El mar enterrado (2005), que se centra en los acontecimientos de la guerra del Pacífico entre Chile y Bolivia. Antofagasta es protagonista de Geología de un planeta desierto (2013), novela que se aleja de los contextos decimonónicos de las novelas previas para centrarse en problemáticas del Chile contemporáneo. La novela se enfoca en la historia de Rodrigo, un geólogo que trabaja en el sector de la extracción de recursos naturales y que, después de varios años viviendo alrededor de América latina, regresa a su ciudad natal. La vuelta a casa le ofrece la posibilidad de reconciliarse con su pasado, revaluar la relación con su difunto padre y de concientizarse de cómo Antofagasta ha sido transformada por el desarrollo de la industria minera.

El tema de la vuelta a casa presente en la novela de Jara es un arquetipo, un 'lugar común', de la generación de escritores conocida como de la 'literatura de los hijos'. La definición inicialmente solía referirse a obras literarias producidas por familiares de víctimas del régimen de Pinochet. Sin embargo, la definición se ha ido extendiendo "hasta incluir [...] a los hijos simbólicos, o sea, [...] las personas de la segunda generación cuya infancia o adolescencia estuvo marcada de alguna manera por la experiencia dictatorial” (Logie y Willem, 2015: 2). Los exponentes chilenos de esta generación son, entre otros, Alejandro Zambra, Lina Meruane, Andrea Jeftanovic, Alejandra Costamagna, Nona Fernández, Rafael Gamucio, Diego Zúñiga y el mismo Patricio Jara (De Querol, 2015). Esta generación de autores y autoras chilenas (y del cono sur en general) escriben de los acontecimientos del Chile dictatorial desde una perspectiva indirecta, ya que vivieron los primeros años de su infancia durante el régimen militar de Augusto Pinochet (1973-1990).

La literatura de los hijos es caracterizada por un estilo híbrido que combina el diario personal con la ficción y una reivindicación de la "legitimidad de su proprio lugar de enunciación" que a menudo se traduce en una postura "revisionista" del Chile de los tiempos de la dictadura (Logie y Willem, 2015: 2-4). Las obras de esta generación también problematizan la cuestión de la perspectiva autorreflexiva, planteando preguntas sobre la legitimidad 
de la voz narradora, particularmente cuando esta no ha sido directamente víctima de la violencia de la dictadura. El tema es particularmente evidente en la novela quizás más representativa de esta generación, Formas de volver a casa (2011) de Alejandro Zambra, en la cual el narrador/autor aborda la problemática de la "falta de muertos" en su familia y de la legitimidad del narrador en contar una historia situada en los años de la dictadura.

La generación de literatura de los hijos es frecuentemente contrapuesta a la generación anterior, surgida con el regreso a la democracia en el 1990, que incluye a autores tales como Diamela Eltit y Germán Marín. Esta generación, denominada de la literatura postdictatorial, surge con la necesidad de procesar los traumas engendrados durante la larga noche trágica de la dictadura (Llanos, 2011: 99) y de "define its position in the new present ushered in by the military regimes: a global market in which every corner of social life has been commodified" (Avelar, 1999: 202). Para enfrentar este doble desafío histórico, la novela postdictatorial elabora "grandes maquinarias alegóricas que intentaban elaborar mecanismos de representación de una catástrofe irrepresentable" de la dictadura (Logie y Willem, 2015: 5). Por el contrario, la literatura surgida con la generación de los hijos aborda el tema del pasado dictatorial con un cambio de paradigma fundamental: "tiende a reescribir la derrota a partir de una experiencia subjetiva del ámbito doméstico" (Logie y Willem, 2015: 5). De este cambio de paradigma deriva el interés por el tema de la "vuelta a casa" del protagonista, topos recurrente de la narrativa de los hijos.

Sin embargo, la perspectiva nostálgica, que tiende a privilegiar una perspectiva subjetiva e intimista, ha sido a menudo asociada con una postura despolitizada, hija del individualismo neoliberal bajo el cual la generación de los hijos ha crecido, dado que:

las tradicionales oposiciones entre opresores y oprimidos, entre victimarios y víctimas, entre idealistas y mercenarios, fueron desplazadas hacia otros territorios: los del erotismo, la marginalidad, el inconsciente, la historia privada, la culpa compartida, la violencia encubierta (García-Corales, 2007: 199).

Según esta interpretación, la 'perspectiva hogareña' de la literatura de los hijos refleja la modalidad nostálgica del posmodernismo teorizada por Frédric Jameson, según la cual el anhelo nostálgico fetichiza la historia y 
resulta en una mirada acrítica y apolítica hacía el pasado (1998: 18-21). En cambio, otras perspectivas críticas sobre la 'generación de los hijos' individúan en el afán de la vuelta a casa la necesidad de reflexionar críticamente sobre el pasado dando voz a una generación que solo había asistido pasivamente a la dictadura y a la continuación de las políticas neoliberales en democracia y que, pero, "refuta [...] enérgicamente las huellas reaccionarias de este pasado que parecen haberse anclado definitivamente en la sociedad chilena" (Willem, 2012: 40). Las/los novelistas de la generación de los hijos centran "su eje discursivo en la memoria y en la escritura, en la escritura de la memoria y en la memoria de escrituras" y "se postulan como versiones inéditas o como versiones alternativas y/o complementarias de la Historia conocida" (Moreno, 2016). Asimismo, el tema de la casa metaforizaría la intrusión de lo político, de la dictadura precisamente, en el ámbito de la vida cotidiana. Contrariamente a la narrativa postdictatorial que reproduce la idea de pérdida del hogar como pérdida de la seguridad personal debido a la violencia de la dictadura, la literatura de los hijos propone una reapropiación de la casa perdida (Logie y Willem, 2015: 5). El arquetipo de la vuelta a casa tendría un potencial simbólico, la superación del duelo que no se produciría en las obras postdictatoriales ya que esas se enfocan principalmente en la parálisis causada por la derrota.

Si bien Geología de un planeta desierto recupera algunos temas y arquetipos de la literatura de los hijos, las reminiscencias del protagonista de Jara no se centran en los traumas del golpe de Estado de Pinochet como suele pasar en las obras de la literatura de los hijos, sino que apuntan a temáticas socioeconómicas. A pesar de la centralidad de temas de carácter íntimo y familiar, Geología de un planeta desierto propone también una mirada crítica sobre los procesos extractivos neoliberales en el norte del país y sus efectos en el tejido urbano y social de Antofagasta y las comunidades de clase obrera del puerto de esta ciudad. De esta manera la novela se distancia de un escapismo individualista y, a pesar de algunas tendencias autoficcionales, propone un dibujo fundamentalmente realista del Chile (y de su norte) contemporáneo y del contexto del capitalismo global. La novela, sin embargo, comienza con una situación paradojal y sobrenatural que produce una situación de extrañamiento:

Las cosas ocurrieron más o menos de este modo: un día, luego de diez 
años muerto, mi papá decidió volver [...] no hubo nada extraño anticipando la situación: sencillamente el viejo estaba allí, tal como lo vestimos en el subterráneo de la morgue; estaba parado frente a mí y ese instante se me hizo eterno [...] «Hola», dijo y avanzó unos pasos hasta el medio del living. «Así que acá vives ahora» (2013: 1).

No obstante, la vuelta a casa del padre (esta vez no de un país extranjero como Rodrigo sino del lejano mundo de los muertos) no disminuye el realismo de la novela, más bien introduce un aspecto metafórico: un regreso de lo reprimido, en términos freudianos, que en este caso no es sólo la relación conflictiva que tuvieron padre-hijo, sino también lo socialmente reprimido, un inconsciente político, para decirlo en palabras de Frédric Jameson (1981). Al respecto, el filósofo estadounidense afirma que la literatura es un acto simbólico social en cuanto, influenciada por la totalidad histórica, esconde a nivel del inconsciente los síntomas de una precisa condición sociohistórica (1981: 1-88). En la novela de Jara la vuelta del padre del mundo de los muertos es una simbolización del inconsciente que incluye no solo aspectos privados y más intimistas sino también aspectos políticos y sociales. Es precisamente la confrontación con lo que el padre representa (una Antofagasta desfigurada por el extractivismo neoliberal) que induce a Rodrigo a revaluar su vida y la existencia en tiempos de capitalismo global y el sistema mismo ya que, describiendo su recorrido alrededor de América Latina, Rodrigo indirectamente plantea dudas y preguntas sobre la sociedad contemporánea y la precariedad existencial engendrada en el sistema del capitalismo global.

Como explica Bauman, la sociedad del capitalismo global, que el sociólogo llama líquida, es caracterizada por la efimeridad de los enlaces sociales (2000: 165) y es dominada por "policy of deliberate precarization" que determina la imposibilidad de estabilidad emocional (2000: 162). Eso aparece evidente en el tercer capítulo, en el cual Rodrigo relata la historia de su relación con Claribel Méndez durante su estancia de trabajo en la República Dominicana, dado que Rodrigo sabe que la relación es temporánea y que despedirse de Claribel sería despedirse de "una mujer a la que muy probablemente nunca más iba a ver" (2013: 15). Asimismo, la imposibilidad de construir enlaces emocionales estables es reflejada en la novela por las continuas mudanzas de Rodrigo alrededor de América Latina (2013: 15-16). 
Sin embargo, la peregrinación de Rodrigo reproduce también la incesante búsqueda de lucro típica del capitalismo global y replica la volatilidad, inestabilidad, efimeridad y la mercantilización de las relaciones humanas bajo un régimen de expansión y conquista de nuevo territorios y expulsión de ciudadanía indeseada (Gago y Mezzadra, 2017: 577). Esta tensión entre expansión y expulsión es claramente representada en la novela por la relación entre Rodrigo y su padre. Por un lado, la actividad de Rodrigo es descrita en términos de conquista:

Los camiones gigantes contra el cerro; las máquinas gigantes, las tolvas gigantes subiendo como escarabajos hacia la montaña que los espera dispuesta a darles pelea. El sonido de los motores, el bramido de la manada contra el silencio del coloso. Así es la minería. Y así también son guerras que duran siglos (2013: 7).

El uso de palabras tales como "pelea", "manada", así como la evocación de un imaginario bélico a través de imágenes de camiones que parecen tanques y la afirmación final "así es la minería. Y así también son las guerras”, relacionan los procesos extractivos con conquistas coloniales de territorios y con la expansión imperial. Por otro lado, la expansión es necesariamente seguida por procesos de expulsión, como en el caso de la ciudad de Antofagasta, que, como nos cuenta Rodrigo "de pronto [...] dejó de ser una ciudad portuaria y se transformó en una ciudad minera” (2013: 23). Dicha transformación determina la expulsión de ciudadanía desechable, representada en el contexto de la novela por la figura del padre. Es precisamente la vuelta de su padre que obliga, entonces, a Rodrigo, hasta este momento participe en los procesos de expansión del capital global en su forma extractiva, a visualizar el impacto de estas prácticas capitalistas. $\mathrm{Al}$ respecto, mirando a unas fotos del pasado, Rodrigo reflexiona:

Todos los amigos que aparecen en la foto de despedida de soltero de mi papá hoy están muertos. Los mató el trago y el tiempo libre que les quedó después de que Pinochet dictara la orden de la primera de las muchas oleadas de jubilaciones anticipadas en la Empresa Portuaria de Chile [...] Ahora que los puertos se iban a privatizar, le dijeron, podrían seguir trabajando como externos, integrarse sin problema en las muchas compañías que prestaban los mismos servicios. Aquello efectivamente fue una opción y como tal duró bastantes años, pero sé que mi papá, aunque 
nunca lo dijo, a veces no soportaba la humillación de que le pagaran por turno trabajando con billetes y monedas dentro de un sobre de café. Tenían que juntar 6 o 7 para tener una cantidad decente (2013: 46).

La novela reproduce la idea que "in this continuous expansion of the frontiers of financial valorization through the "colonization" of social territories outside of finance's command, an extractive dimension of financial operations gradually appears" (Gago y Mezzadra, 2017: 581), ya que en el párrafo previamente citado se revelan los enlaces entre el desarrollo de prácticas extractivas y procesos propiamente financieros del capitalismo global, tales como el desmantelamiento de comunidades obreras, la externalización y la precariedad laboral.

El despojo de un territorio y el consecuente desalojo evidencian las lógicas intrínsecamente extractivas de la financialización de la economía (Sassen 2010: 27) que se manifiestan a través de los mecanismos de endeudamiento, eje central del sistema de relación de clase en el capitalismo contemporáneo; como afirma Lazzarato: "the subjective achievements neoliberalism had promised ('everyone a shareholder, everyone an owner, everyone an entrepreneur') have plunged us into the existential condition of the indebted man, at once responsible and guilty for his particular fate" (2012: 8-9). En la novela, Rodrigo subraya el uso de los procesos de endeudamiento como sistema de expulsión cuando describe los acontecimientos que derivan del endeudamiento de su familia: [e]l boom de las financieras a inicios de los 90 y mi papá pidiendo préstamos uno tras otro hasta llegar a ocho [...] el viejo encalillado por dos años y mi mamá quitándole mes a mes la jubilación para pagar las deudas y organizar los gastos" (2013: 46). La deuda de la familia de Rodrigo es esencialmente una forma de biopoder regulatorio, tal como describe Lazzarato: "debt directly entails life discipline and a way of life that requires 'work on the self' a permanent negotiation with oneself, a specific form of subjectivity" (2012: 104). Rodrigo describe dicho efecto bio-regulatorio del endeudamiento trazando una conexión entre este y el desencadenamiento del alcoholismo y del deterioro psíquico y físico del padre: "fue por aquel tiempo cuando al viejo le sobrevino una hinchazón en su abdomen; una falla hepática hizo que lentamente se llenara de líquido [...] A eso se agregó una implacable dermatitis en ambas piernas" (2013: 46). 
En su libro Capitalist Realism (2009), Mark Fisher discute la correlación entre el incremento exponencial de condiciones tales como la depresión o la ansiedad y el neoliberalismo (19). Asimismo, el crítico afirma que, bajo dicho sistema, se produce una "privatización del estrés" que invalida cualquiera explicación social de los orígenes de la que él define como una pandemia de depresión (21). La privatización de la enfermedad, consecuentemente, impide una politización de las causantes del surgimiento y la difusión incontrolada de problemáticas psicofísicas (21). Por lo tanto, al trazar una línea directa entre enfermedades padecidas por el padre de Rodrigo y las causas sociales de su alcoholismo, la novela propone una lectura que se distancia de interpretaciones intimistas y propone una lectura intrínsecamente política de los acontecimientos narrados. Por lo tanto, la afirmación "todos los amigos que aparecen en la foto de despedida de soltero de mi papá están muertos” (2013: 22) va más allá del añoro nostálgico por un pasado perdido, ya que describe el proceso de olvido que aflige a la comunidad obrera de Antofagasta. En otras palabras, en la novela se produce una yuxtaposición entre la modalidad nostálgica típica de la mirada de la literatura de los hijos y la crítica sociopolítica. En este sentido, cuando Rodrigo relata que su estancia al extranjero termina "cuando se concretó una serie de proyectos de exploración concentrados al interior de Antofagasta, la capital mundial de la minería", añade también que le "hubiese gustado que fuera volver a casa, pero aquí ya no queda nada de eso" (2013: 16). Si bien hay una mirada nostálgica hacía una casa que ya no existe por el hecho de que su "mamá y [...] hermana se fueron hace tiempo, han hecho su vida a miles de kilómetros de acá" (2013: 16), la idea de casa desaparecida, inimaginable o desimaginada está también relacionada con los efectos socioeconómicos del extractivismo, ejemplificados por la descripción del abandono y negligencia social que han afectado el barrio obrero en el cual él había crecido, que una vez había sido un bastión de resistencia contra la dictadura -“[d]urante el tiempo de los milicos, estos murallones sirvieron para las consignas contra Pinochet. Casi todas aparecían escritas a la mañana siguiente de las noches de cacerolazos" (2013: 68)- afirma Rodrigo, como consecuencia del desmantelamiento de las actividades en el puerto de la ciudad. Sin embargo, con la expansión del proyecto neoliberal y extractivo y con la trasformación del tejido urbano y social, la comunidad se ha ido fragmentando. En palabras de Rodrigo: 
A medida que la primera generación de vecinos envejeció, la tierra y el polvo avanzaron hasta rodearlo todo. Ha sido un proceso lento pero inevitable [...] Es mucho peor y mucho más definitivo que el aluvión del 1991. Aquella vez todo se embarró [...] y ese barro, a las semanas, era una cubierta de tierra seca entre todos los vecinos sacaron a paladas. Pero hoy esa gente está muy vieja para impedir algo así: cojos [...] encorvados van y vienen con sus bolsas de genero desde la feria o desde algunos de los pocos almacenes que van quedando luego de la llegada de los grandes supermercados (2013: 68).

Lo que Rodrigo relata es, en otras palabras, el proceso que ha transformado el barrio de Antofagasta donde creció en lo que Rob Nixon denomina "comunidad desimaginada" ("unimagined community") (2011: 150), definida como aquella comunidad que es sacrificada por el capitalismo, a través del poder del Estado, para fines de supuesto desarrollo económico como la construcción de represas o proyectos de extracción. Como explica el crítico estadounidense, conjuntamente a la violencia 'física' que se manifiesta con a la intervención militar y el desalojo, hay una violencia, definida por el como lenta "(slow)" que se manifiesta a través del olvido burocrático, la invisibilización mediática, la falta de intervención social y la contaminación ambiental: "[t]he result is [...] called spatial amnesia, as communities, under the banner of development, are physically unsettled and imaginatively removed" (2011: 150-151). El resultado es la creación de comunidades fantasmas (Nixon 2011: 151) como el barrio descrito por Rodrigo: "[a]sí se mueven los vecinos del barrio, lentos, como fantasmas a plena luz del día, caminando allí donde la tierra se ha comido los antejardines y las escaleras de entrada a los edificios" (2013: 68).

Tales referencias a elementos fantasmales, epitomizado por el personaje del padre, dentro de una narración realista con fuertes elementos de crítica social responden a la urgencia de manifestar las "recurrent anxieties about corporeal dismemberment in societies where the commodification of human labour - its purchase and sale on markets - is becoming widespread" (McNally, 2011: 4). El capitalismo es esencialmente mágico, afirma McNally, ya que sus lógicas fundamentales se basan en la ocultación de las dinámicas de transacción entre el cuerpo humano (fuerza de trabajo) y el capital (2011: 114). Asimismo, el gran poder del capital se basa en invisibilización de sus dinámicas que, sustentado por el sentido común burgués que 
naturaliza las dinámicas de explotación como si fueran dinámicas propias de la existencia humana: "[f]or capital's great powers of illusion lie in the way it invisibilises its own monstrous formation" (McNally, 2011: 114). Por ende, mientras que capitalismo trata de esconder los fantasmas de su lógica utilitarista, enfrentarlos significa poner en manifiesto las dinámicas de explotación del capital: "[t]o name these horrors is also to perform a counter-magic to the sorcery of capital” (McNally, 2011: 114). Por esa razón, afirma McNally, en un texto eminentemente materialista como El capital de Marx abundan referencias a monstruos, fantasmas, vampiros y demás creaturas del horror: descripciones de la condición de vida de los obreros de la Inglaterra del siglo XIX repletas de alusiones a lo paranormal con las que Marx ha evidenciado los signos de la monstruosidad de la explotación en el cuerpo de la clase obrera: "[r]ather than merely provocative metaphors, then, Marx's monsters are signs of horror, markers of the real terrors of modern social life" (McNally, 2011: 115). De forma análoga, la novela describe la minería como un animal feral y misterioso, como el monstruo mitológico de la antigua Grecia, el uróboro, la serpiente que devora su propia cola simbolizando el eterno ciclo del universo: "[1]a minería es un animal que se alimenta de su propia cola” (2013: 63). En el caso específico de la novela, el uróboro representa el monstruo de capitalismo que se nutre incesantemente del ambiente en sus continuos ciclos de extracción, producción, consumo y destrucción. Si bien en El capital, Marx trata de producir un efecto de extrañamiento en el lector para contrastar la normalización de los ciclos del capitalismo, tratando de-familiarizarlo y obligarlo a ver la realidad bajo el capitalismo por lo que realmente es, en la novela de Jara, el fantasma del padre obliga a Rodrigo y a los lectores, a enfrentar el horror de la disgregación social producida por las dinámicas del capitalismo global. En novela existe una "estructura metafórica de substitución" (que McNally atribuye a la escritura de Marx) a través de la cual, "una cosa (el dinero) representa otra (la mercancía)" [mi traducción]. Este fenómeno metafórico se produce gracias al mecanismo de extrañamiento, instrumento narrativo propio del género gótico, según el cual "a doubling process in which the truth of one thing or agent can only be arrived at through another which stands in opposition to it" (McNally, 2011: 114). En el contexto de la novela, la referencia al cementerio como elemento de comparación para describir la disgregación social y el descuido debido a falta de fondos que 
afecta Antofagasta es un instrumento que recupera figuraciones del género del gótico en el cual el cementerio es un espacio arquetipo:

Durante aquellos días fuimos dos veces al cementerio, esa pequeña ciudad amurallada que [...] tiene más construcciones de cemento, más paredes pintadas, más vegetación y calles pavimentada que muchos de los barrios populares que lo circundan (2013: 26).

En el contexto social del capitalismo global, ser realista se vuelve un sinónimo de austeridad fiscal y recortes de servicios públicos (aludidos en el párrafo mencionado arriba); imaginar una alternativa a tal "régimen moral" es considerado inasequible e irrealista (Shonkwiler y La Berge, 2014: 2). Por esta razón, la introducción del elemento fantasmal, en la novela de Jara, no solo tiene el propósito de producir un elemento metafórico para visibilizar los efectos sociales de la abstracción del capital sino también es un mecanismo de resistencia a tal realismo capitalista. Como escribe Jameson discutiendo Cien años de soledad, el aparato mágico sirve para reproducir los esfuerzos de las populaciones afectadas por los procesos del capitalismo de encontrar sentido en los fenómenos de los cuales son testigos y víctimas (2017). Asimismo, en Cien años de soledad (1967), cuando se cuenta que Macondo está destinado a ser aniquilado por "un pavoroso remolino de polvo y escombros centrifugado por la cólera del huracán bíblico" (843), esta célebre evocación del poder destructivo y casi sobrenatural de los huracanes funciona como metáfora del impacto de la explotación de los recursos naturales en el tejido social de las sociedades latinoamericanas. Asimismo, en la novela de Jara, además de la presencia de fantasmas, Rodrigo propone visiones de destrucción y olvido cuando describe el barrio obrero de Antofagasta:

Hay bolsas con pegamento, condones, toallas higiénicas sucias, cajas de vino aplastadas y con impresos decolorados, latas de cerveza, restos de vidrio, manchas de sangre seca. Alguna vez alguien encontró un puñado de billetes de mil pesos embetunados con mierda. Pero nada de lo que allí se podía encontrar, ninguno de los cuentos sobre las cosas que pasaban allí arriba se compara con el miedo que teníamos todos: que con algún temblor el estanque se viniera rodando en picada hacia los edificios como una bola contra de los palitroques (2013: 67). 
Tales descripciones casi-apocalípticas, sin embargo, para adaptar las palabras de Deckard para describir los elementos catastróficos y supernaturales en la ficción de Miguel Asturias, "it is not an apocalyptic capitulation to the impossibility of imagining a better future but rather the use of an irrealist, liminal event to rearrange briefly the conditions of the possible" (2016: 37). Es entonces el aspecto "irrealista" de la novela, el encuentro de Rodrigo con el fantasma de su padre, el cual ofrece la posibilidad de re-imaginar las desimaginadas comunidades obreras del puerto de Antofagasta:

Hoy sería capaz de describir exactamente cómo era el puerto de Antofagasta antes de que lo privatizaran y la mitad de su terreno fuese destinado a un centro comercial. Sería capaz de dibujarlo tal como alguna vez lo hice en el colegio [...] Recuerdo que el profesor [...] llegó a decirme que le contara la verdad. Le contesté que mi papá trabajaba en esas gruas (2013: 23).

Después de haber encontrado al fantasma, Rodrigo puede imaginar nuevamente a su ciudad y a su padre como obrero del puerto: lo irreal, por lo tanto, a través de una figuración simbólica, ofrece la posibilidad de desarrollar una conciencia social y, consecuentemente, de desafiar el realismo capitalista. Es a través de este encuentro con la "irrealidad" que Rodrigo logra visualizar la abstracción capitalista en la materialidad de la práctica extractiva y toma conciencia de su posición en el ciclo del capitalismo global. Dicha concientización se presenta a través de otra metáfora que, siendo Rodrigo un geólogo, recurre a un lenguaje geográfico y geológico:

En este instante mi ubicación exacta es $22^{\circ} 22$ '50"; $68^{\circ} 23$ '23.61" O. [...] un destello sobre el lomo verdoso del Gran Metalotecto, el lugar donde hay más cobre en el mundo (2013: 74).

La precisión con la cual Rodrigo señala su posición en el desierto de Atacama resalta la centralidad de este territorio en la historia del capitalismo en Chile, el lugar donde la historia de explotación minera se cruza con la historia de los desaparecidos del régimen de Pinochet, como nos recuerda el dramaturgo Ariel Dorfmann en su libro de no ficción Desert Memories (2004). El recorrido de Dorfmann en el Norte Grande de Chile 
y el descubrimiento de las grandes ambiciones de la industria minera se enlazan con la búsqueda del cuerpo del amigo del escritor, Freddy Taberna, asesinado por la dictadura y desaparecido. Igualmente, en el documental de Patricio Guzmán, Nostalgia de la luz (2010), se produce una dicotomía entre la mirada hacía las estrellas de los astrólogos que buscan de reconstruir el origen, el pasado, de la humanidad y la búsqueda de los desaparecidos por un grupo de mujeres. El largometraje de Guzmán "[f[ilma los cuerpos de los mineros, las momias, las pinturas rupestres. Si algunas huellas de esta catástrofe resisten al paso del tiempo, otras están desapareciendo, han sido borradas, o quedan voluntariamente ocultas" (Pugibet, 2016: 192). Las huellas borradas de los desaparecidos que las mujeres buscan encontrar para reconstruir no solo la historia individual de las víctimas de la dictadura, sino que estas huellas sirven también para reconstruir una historia colectiva. Por esa razón, en los párrafos finales de la novela, antes de despedirse de su padre, Rodrigo toma nota de su posición exacta en el desierto de Atacama:

Un lugar exacto [...] anoté en un papel por si la máquina que uso para estas cosas me traicionaba, por si se borraba lo que nunca se debía borrar: $-24-161516 /-40-150409(2013,80)$.

En el desierto de Atacama la abstracción de las teorías neoliberales se hace materialidad y deja huellas que indican una historia que nunca se debe borrar, como pronuncia Rodrigo. Es en esta confluencia de procesos de explotación capitalista y violencia dictatorial que se encuentra la raíz de la historia contemporánea de Chile y de los conflictos sociales actuales. "La pena es un planeta desierto" (2013: 81), como afirma Rodrigo en la conclusión de la novela, es una afirmación que confirma que el proceso de concientización se ha cumplido: el fantasma del padre puede finalmente regresar al mundo de los muertos. La irrealidad deja espacio a la realidad (social y política) desvelada. El aspecto "irreal” y el mecanismo narrativo metafórico del fantasma para revelar las raíces históricas de la condición social del presente, actúan como un mecanismo de crítica del realismo capitalista entendido como el consenso hegemónico alrededor de la imposibilidad de imaginar una alternativa al neoliberalismo. Igualmente, la búsqueda de la identidad personal presente en la novela, que es un arquetipo de la litera- 
tura de los hijos, inicia "un movimiento de análisis y de redescubrimiento" (Moreno, 2016) no solo de una historia intima, familiar, sino también de la historia colectiva del país. Sin embargo, mientras que normalmente la novela de los hijos se enfoca en reevaluar momentos claves de la historia de Chile, particularmente el golpe de Estado de Pinochet y los años de la dictadura, en Geología de un planeta desierto el periodo de la dictadura aparece solo tangencialmente en el enfoque de la historia. En cambio, la novela de Jara se centra particularmente en contar, reevaluar y criticar el sistema socioeconómico neoliberal chileno y el papel de la minería en Chile en el capitalismo global. En el contexto de la novela, si bien la dictadura es mencionada como un momento crucial del desarrollo de dicho sistema, no constituye el fulcro de la narración. Por lo tanto, contrariamente a novelas tales como Formas de volver a casa de Zambra (2011), que se enfocan en una relectura del pasado, la novela de Jara propone una crítica social del Chile del presente.

\section{Referencias}

Avelar, I. (1999). Restitution and Mourning in Latin American Postdictatorship. Boundary 2,26.3: 201-224.

Bauman, Z. (2000). Liquid Modernity. Cambridge: Polity.

Deckard, S. (2016). The Political Ecology of Storms in Caribbean Literature. En Campbell, C. y Niblett, M. (comp.) The Caribbean Aesthetics, World-Ecology, Politics. Liverpool: Liverpool University Press.

De Querol, R. (2015). Los niños de la represión chilena llenan los silencios. El País. Recuperado de: https://elpais.com/cultura/2015/o6/o9/babelia/1433843677_532023.html.

Dorfmann, A. (2004). Desert Memories Journeys Through the Chilean North. London: Penguin Random House.

Fisher, M. (2009). Capitalist Realism. London: Zero Books.

Gago, V., Mezzadra, S. (2017). A Critique of the Extractive Operations of Capital: Toward an Expanded Concept of Extractivism. Rethinking Marxism 29:4, 574-591, DOI: 10.1080/08935696.2017.1417087.

García-Corales, G. (2007). El debate cultural y la literatura chilena actual: Un diálogo con cinco generaciones de escritores. Lewiston: Mellen. 
García Márquez, G. (1967). Cien años de soledad. Ciudad de México: Alfaguara. [Versión EPUB].

Jameson, F. (1981). The Political Unconscious: Narrative as a Social Symbolic Act. London: Methuen.

. (1998). The Cultural Turn: Selected Writings on the Postmodern, 1983-1998. London: Verso.

. (2017). No Magic, No Metaphor. London Review of Books

39:12. Recuperado de: https://www.lrb.co.uk/the-paper/v39/n12/ fredric-jameson/no-magic-no-metaphor.

Jara, P. (2002). El sangrador. Ciudad de México: Planeta.

. (2005). El mar enterrado. Ciudad de México: Alfaguara.

- (2013). Geología de un planeta desierto. Ciudad de México: Alfaguara. [Versión EPUB].

Llanos. B. (2011). Family Imaginaries and Postmemory in Chilean Narrative: Andrea Jeftanovic's Escenario de guerra and Lina Meruane's Cercada. En Román-Odio, C. y Sierra, M. (comp.) Transnational Borderlands in Women's Global Networks: The Making of Cultural Resistance (pp. 99-118). Londres: Palgrave.

Lazzarato, M. (2012). The Making of the Indebted Man: An Essay on the Neoliberal Condition. Los Angeles: Semiotext(e).

Logie, I., Willem, B. (2015). Narrativas de la postmemoria en Argentina y Chile: la casa revisitada. Alter/nativas 5: 1-25.

McNally, D. (2011). Monsters of the Market: Zombies, Vampires and Global Capitalism. Amsterdam: Brill.

Moreno, F. (2016). Acerca de la Literatura e Historia en la narrativa de post dictadura. Letras de Chile. Recuperado de: https://letrasdechile. cl/home/index.php/ensayos/420-acerca-de-la-literatura-e-historiaen-la-narrativa-de-post-dictadura.html.

Nixon, R. (2011). Slow Violence and the Environmentalism of the Poor. Cambridge MA: Harvard University Press.

Pugibet, V. (2016). Memorias de catástrofes en Nostalgia de la luz (Patricio Guzmán, 2010).Iberic@l, Revue d'études ibériques et ibéro-américaines 10: 187-206.

Sachse, R. (Productor), Guzmán, P. (Director). (2010). Nostalgia de la luz [Película]. Chile, Francia y Alemania: Blinker Filmproduktion / WDR / Cronomedia / Atacama Productions. 
Sassen, S. (2010). A savage sorting of winners and losers: Contemporary versions of primitive accumulation. Globalizations 7 (1-2): 23-50.

Shonkwiler, A., La Berge L.C. (2014). Reading Capitalist Realism. Iowa City: Iowa University Press.

Willem, B. (2012). Metáfora, alegoría y nostalgia: La casa en las novelas de Alejandro Zambra. Acta Literaria 45: 25-42.

Zambra, A. (2011). Formas de volver a casa. Barcelona: Anagrama. [Versión EPUB]. 